Article

\title{
Technical Efficiency and Its Determinants of Rice Production in Cambodia
}

\author{
Sokvibol Kea ${ }^{1,2, *}$, Hua $\mathrm{Li}^{1, *}$ and Linvolak Pich ${ }^{3}$ \\ 1 College of Economics and Management (CEM), Northwest A\&F University, 712100 Shaanxi, China \\ 2 Faculty of Sociology \& Community Development, University of Battambang, 053 Battambang, Cambodia \\ 3 College of Water Resources and Architectural Engineering (CWRAE), Northwest A\&F University, \\ 712100 Shaanxi, China; pichlinvolak@yahoo.com \\ * Correspondence: keasokvibol@yahoo.com (S.K.); lihua7485@163.com (H.L.); \\ Tel.: +855-96-986-6668 (S.K.); +86-133-6393-6398 (H.L.)
}

Academic Editor: David O. Dapice

Received: 31 July 2016; Accepted: 27 September 2016; Published: 3 October 2016

\begin{abstract}
The present study aims to measure the technical efficiency and establish core factors affecting rice production in Cambodia. A four-year dataset generated from the central government document "Profile on Economics and Social" of 25 entire provinces between 2012 and 2015 and the stochastic production frontier model (SFA) was applied. The results indicated that the level of output (quantity) of Cambodian rice production varied according to the different level of capital investment in agricultural machineries, total rice actual harvested area, and technical fertilizer application within provinces. Furthermore, evidence revealed that the overall mean efficiency of rice production is $78.4 \%$, which implies that there is still room to further improve technical efficiency given the same level of inputs and technology. More importantly, the findings revealed that irrigation, production techniques and amount of agricultural supporting staff are the most important influencing factors of rice production's technical efficiency in Cambodia. In conclusion, the present study strongly recommends the development of irrigation systems and good water management practices to be considered and bring about more effective actions by the central government as well as related agencies for improving rice production in Cambodia in addition to capital investment and improving technical skills of supporting staff and rural farmers.
\end{abstract}

Keywords: technical efficiency; SFA, rice production; Cambodia; agriculture; productivity

JEL Classifications: C01; C33; C51; C87; E23; M11; O33

\section{Introduction}

The Cambodian economy is largely dependent on the agricultural sector, which contributes $27 \%$ of national GDP (Gross Domestic Product), in which 65\% of the labor force are engaged [1]. Growth in the agricultural sector has played a crucial role in the development of Cambodia [2]. Since 2004, garments, construction, agriculture, and tourism have driven Cambodia's growth. Between 2010 and 2013, GDP climbed more than 7\% annually [3], and GDP per capita in purchasing power parity has increased from \$2,462 (US Dollar) in 2010 to $\$ 3,056$ in 2013 [4]. However, although Cambodian's per capita income is rapidly increasing, it still remains low compared to other nations in the region. Most rural households depend on agriculture and its related sub-sectors; and rice, fish, timber, garments and rubber are Cambodia's major export products [3].

Rice production is central to the Cambodian agricultural sector, and not only do the majority of Khmer farmers depend both directly and indirectly on the success of the rice crop each year, but as it is the main food staple, rice production is a big factor in the national effort to promote food security. 
It occupies more than $80 \%$ of total cultivated land and is the most important agricultural export commodity, as well as the main source of crop value added and the major driver of agricultural growth [5]. Being one of the most important staple crops for human consumption, rice plays an unprecedented role in combating food insecurity. Furthermore, rice has become a key economic crop that dominates most agricultural economies in the world, particularly in developing countries like Cambodia.

Having similar characteristics to other agricultural crops, nowadays the growth of rice production yield seems to depend on three important aspects: (a) enlarging planting areas; (b) increasing input of material factors; and (c) raising productivity gradually [6]. Due to the limitation of planting area and material input factors, along with the result of rapid population growth from 11.4 million in 1998 to 15.5 million in 2014 [7,8] and, thus, an increasing demand of land areas and material input factors for non-farm activities, raising productivity of rice production should be the most preferable factor among the three factors previously described.

Khmer farmers have been growing rain-fed rice for at least 2000 years, possibly longer in the case of upland rice [9]. Today, rice production still serves as the foundation of Cambodian economy. Between 1980 and 2010, rice production yield has been doubled from 1.21 tons/ha to 2.97 tons/ha [10]. However, productivity of Cambodian rice still has been relatively low compared to other Asian countries, such as Myanmar, Indonesia, Vietnam, Japan, South Korea, and China, where rice productivity in 2010 was recorded 4.12 tons/ha, 5.01 tons/ha, 5.32 tons/ha, 6.51 tons/ha, 6.51 tons/ha, and 6.55 tons/ha, respectively [11]. Therefore, in order to raise the productivity of rice production in Cambodia, it is important to identify the core factors influencing it.

The main objective of this study was to measure the technical efficiency (hereafter, TE) of rice production in Cambodia. Additionally, the study was also trying to identify core influencing factors of TE in order to explain the possibilities of increasing productivity and profitability of rice by increasing efficiency at provincial level, as well as identify what technical progress policy should be recommended to help decision makers increase the rice productivity in Cambodia. The results of this study will be useful for both rice producers and policy makers in government and all other stakeholders along the rice value-chain including development agencies, non-government organizations (NGOs), and many other related parties working towards improving rice production and the agricultural sector at large.

The rest of this article is organized as follows: Section 2 presents analytical frameworks and methodology for measuring rice production TE, while in Section 3, the data and descriptive statistics of output and input variables is presented. The results are presented, compared, and discussed in Section 4. Finally, concluding remarks are offered in Section 5.

\section{Methodology}

In the economics literature, productivity refers to the amount of output(s) obtained from given levels of input(s) in an economy or a sector. It is an important topic of study, since productivity is one of the two fundamental sources of larger income streams; the other being savings, which permit more inputs for employment [12]. Coelli and Rao [13] argued that productivity is the ratio of the output(s) that it produces to the input(s) that it uses (Productivity = Output(s)/Input(s)). In other words, productivity is raised when growth in output(s) outpaces growth of input(s). Productivity growth without an increase in input(s) is the best kind of growth to aim for rather than attaining a certain level of output [14]. Nevertheless, measuring the total input and total output is both conceptually and empirically difficult. Methods to estimate productivity and efficiency that are commonly and frequently implemented in most of today's empirical works are data envelopment analysis (DEA) and stochastic frontier analysis (SFA), which are non-parametric approaches and parametric approaches, respectively.

Between DEA and SFA, which method should be chosen often depends on the application being considered. The SFA is recommended by Coelli [15] for use in most agricultural applications. This method has the added advantage of permitting the conduct of statistical tests of hypothesizes regarding the production structure and the degree of inefficiency. However, if an application is 
using farm level data where measurement error, missing variables (e.g., data on an input is not available or not suitably measured), weather, etc. are likely to play a significant role, then the assumption that all deviations from the frontier ${ }^{1}$ are due to inefficiency, which is made by DEA, may be a courageous assumption. Thus, only a small percentage of agricultural frontier applications have used the DEA approach for frontier estimation. However, DEA has a very large following in other professions, especially in the management science literature, and in applications to service industries where there are multiple outputs, such as banking, health, telecommunication and electricity distribution, including [16-20], etc. Another benefit of the SFA approach is determinants of inefficiency, which allowed external factors affecting efficiency of firms to be determined where unavailable in the DEA approach. SFA, hence, was applied by a large number of papers in the recent years, particularly in agricultural research. For instance, the studies that have implemented the SFA approach include [21-24], etc. Furthermore, detailed discussion of the differences between DEA and SFA has been given in Coelli [15]. Therefore, SFA was also being applied to the present study.

Productivity and efficiency studies have taken the attention of most economists and policy makers in recent years, since there is no meaningful welfare improvement and economic development can take place in the absence of productivity growth [10]. Productivity is a basic and intuitive measure of performance. Furthermore, total factor productivity $\left(\mathrm{TFP}^{2}\right)$ is a method of measuring business performance. TFP is used both in competitive and regulated industries, such as electricity distribution companies [26], for instance. It is a method of measuring productivity and growth, which is a productivity measurement involving all factors of production. Other traditional measures of productivity, such as labor productivity in a factory, fuel productivity in power stations, and land productivity (yield) in farming, are often called partial measures of productivity. These partial productivity measures can provide a misleading indication of overall productivity when considered in isolation [27].

However, agricultural productivity and efficiency studies as well as rice production efficiency studies in Cambodia seem to be very poor. Most research works were conducted by the related government agencies, such as the National Institute of Statistics (NIS), the Ministry of Agriculture, Forestry and Fishery (MAFF), Cambodia Development Resource Institute (CDRI), Cambodia Agricultural Research and Development Institute (CARDI), etc. Thus, only a few research works were conducted by the scholars. Given the scarcity of literature on efficiency in Cambodia, the present study, therefore, seeks to augment literature and contribute in many ways to bridge the gap and supplement the shortage.

The objective of this study was achieved through the estimation and analysis of the stochastic production frontier model (hereafter, SFA model), originally proposed by Aigner, Lovell [28], and Meeusen and Van den Broeck [29]. The most commonly used package for estimation of SFA model is FRONTIER 4.1c (see Coelli [30]). The general form of the SFA model:

$$
\operatorname{Ln} y_{i t}=\operatorname{Ln} f\left(x_{i t}, t ; \beta\right)+v_{i t}-u_{i t},
$$

where $L n$ indicates the natural logarithm function form; $y_{i t}$ and $x_{i t}$ denotes rice production output(s) and input(s) within period $t$, respectively; $\beta$ represents estimated coefficients; $v_{i t}$ is statistical random error, assumed to be normal distribution, $v_{i} \sim N\left(0, \sigma_{v}^{2}\right) ; u_{i t}$ denotes technical inefficiency, assumed to be truncated normal distribution, $u_{i} \sim\left|N\left(0, \sigma_{u}^{2}\right)\right| ; v_{i t}$ and $u_{i t}$ are assumed to be independent; $i=1,2, \ldots, N ; N$ is number of measurement unit $\left(M U_{i}\right)$, i.e., total samples; and $t$ is time variable measured as year, $t=1,2, \ldots, T$.

1 According to [15]. "Frontier" refers to a bounding function, which provided benefits of heavily influencing of the best performing firms in in a field (of economics), that always reflect the technology they are using. Additionally, the frontier function represents a best-practice technology against which the efficiency of firms within the industry can be measured.

2 Also called multi-factors productivity (MFP) in some lectures, like [25]. 
The present study utilized the logarithmic form of translog production function, thus Equation (1) above can be written as:

$$
\operatorname{Ln} y_{i t}=\beta_{0}+\sum_{j} \beta_{j} \operatorname{Ln} x_{j i t}+\beta_{t} \mathrm{t}+\frac{1}{2} \sum_{j} \sum_{k} \beta_{j k} \operatorname{Ln} x_{j i t} \operatorname{Ln} x_{k i t}+\frac{1}{2} \beta_{i t} t^{2}+\sum_{j} \beta_{j t} \operatorname{Ln} x_{j i t} t+v_{i t}-u_{i t} .
$$

The technical inefficiency effect can be expressed in following general form:

$$
u_{i t}=\delta_{0}+\sum_{k=1}^{n} \delta_{k} z_{k i t}+\omega_{k i t}
$$

where $\omega_{k i t}$ is the stochastic noises; $z_{k i t}$ denotes exogenous variables that are factors affecting Cambodia's rice production TE; $\delta_{0}$ and $\delta_{k}$ are estimated coefficients; if $\delta_{k}$ is negative indicates positive relationship between affecting factor variables and TE of rice production, conversely, if $\delta_{k}$ is positive shows negative relationship between TE and affecting factors.

Followed by Equations (2) and (3), the parameters estimation of SFA model can be achieved by applying the maximum likelihood estimation method, which estimates the likelihood function in terms of two variance parameters (see Coelli [31]):

$$
\gamma=\sigma_{u}^{2} / \sigma_{s}^{2} ; \sigma_{s}^{2}=\sigma_{v}^{2}+\sigma_{u}^{2}
$$

Gamma $(\gamma)$ takes values between zero and one $(0 \leq \gamma \leq 1)$, and reflects validity of the random disturbances $\left(v_{i}, u_{i}\right)$ proportion. If $\gamma$ is closer to zero, it indicates that the gap between actual output and the maximum possible output mainly comes from other uncontrolled pure random factors, which makes the use of stochastic frontier model meaningless. In contrast, if $\gamma$ is closer to one, it shows that the gap comes mainly from the effects of one or more exogenous variables. $z_{k i}$, indicates that using stochastic frontier production function model is more appropriate.

Rice production TE of every $M U_{i}$ can be estimated by the ratio of observed output relative to the potential output defined by SFA model, as follows:

$$
T E_{i t}=y_{i t} / f\left(x_{i t}, t\right)=\exp \left(-u_{i t}\right) \leq 1
$$

TE value is always smaller or equal to one. When TE is equal to one, it indicates $M U_{i}$ in the samples is fully technically efficient. Therefore, the closer the TE value is to one, the higher TE of rice production.

Technical efficiency change (hereafter, TEC) of every $M U_{i}$ between period $t$ and $t+1$ is the ratio of TE in period $t+1$ to its TE in period $t$, which can be expressed as the following formula:

$$
T E C_{i}^{t, t+1}=T E_{i}^{t+1} / T E_{i}^{t}
$$

\section{Data and Descriptive Statistics}

Data used for the present study were drawn from the document sets of the Royal Government of Cambodia (hereafter, RGC), namely "Profile on Economics and Social" of 25 entire provinces in Cambodia (24 provinces and one municipality, Phnom Penh) from 2012 to 2015 (four-year dataset) [32,33]. These document sets were prepared by the Provincial Department of Planning of every province based on computer programs, namely the Commune Database (CDB) that provided derived data from village and commune data books that are annually documented and kept at communes/sangkats and with the village chiefs or village representatives that are members of the Planning and Budgeting Committee.

The SFA model was constructed by one output variable (i.e., quantity) and five input variables, including land, labor, fertilizer, pesticide, and machinery. The output variable was the total provincial un-milled rice production quantity (hereafter, rice output), which was measured in tons. Land input was the total area of rice actually harvested within the year, measured in hectares (ha). In many agricultural nations, land always plays as an important input in production of agricultural crops like rice. Countries 
harvested larger areas of rice tend to be able to produce higher amounts of rice output, for example, Thailand and Indonesia, where about 10-12 million hectares of rice was harvested annually compared to Cambodia that could harvest only 2-3 million hectares per year. Thus, production of rice in these two countries were, respectively, recorded at around 20 and 36 million tons (of milled rice) annually, compared to only around 4 million tons per year produced in Cambodia [34]. Additionally, provinces of Cambodia that harvested more areas of rice were also able to produce more rice output compared to provinces with lower rates of rice-harvested land. For instance, the province of Battambang and Prey Veng, where around 279 and 268 thousand hectares of rice area were, respectively, harvested in 2015, produced more than 798 and 803 thousand tons of rice output (respectively), which was much higher compared to Phnom Penh suburbs that harvested only 11 thousand hectares and produced about 2 thousand tons within this year [33]. Harvested area (i.e., land input), hence, was expected to have positive effects on provinces as well as total rice output. Labor input, on the other hand, measured as total farmers with rice farming as primary occupation (hereafter, rice farmers), unit in persons. According to the dataset from RGC [32,33], provinces with higher rates of rice farmers tended to produce higher amounts of rice output, since rice remains as their provincial dominant crop as well as the dominant commodity. Thus, labor input was also expected to have a positive effect on rice output. Furthermore, fertilizer input was measured as the total amount of chemical and organic fertilizer quantity use by total families cultivating rice (hereafter, rice families) in the province (unit in tons), while pesticide input was also measured as the total amount of poison for insect and grass quantity (for both chemical and organic poisons) use by total rice families in the province, units in tons. Followed by the concept of the green revolution [35], these two input variables were also expected to be positively related to rice output. Additionally, another important input variable was determined as the variable of capital investment on agricultural machineries, which was measured as the total amount of tractors, walking tractors ("koryons" in Khmer language), and rice transplanting machines existing in the provincial territory. This input variable was also expected to have a positive effect on rice output as well. Along with the global technological expansion, the development of agricultural sector was inevitably linked to the mechanization improvement as many works/tasks in agricultural production, particularly rice production in Cambodia (which normally is labor-intensive), could be completed faster and greater with the performances of these machineries. Table 1 provides summary statistics of the output and inputs of rice production within entire 25 provinces in Cambodia from 2012 to 2015.

Table 1. Input and output summary statistics for 25 rice producing provinces in Cambodia, 2012-2015.

\begin{tabular}{|c|c|c|c|c|c|c|c|c|}
\hline \multirow{2}{*}{ Variable } & \multicolumn{2}{|c|}{2012} & \multicolumn{2}{|c|}{2013} & \multicolumn{2}{|c|}{2014} & \multicolumn{2}{|c|}{2015} \\
\hline & Mean & S.E. & Mean & S.E. & Mean & S.E. & Mean & S.E. \\
\hline $\begin{array}{c}\text { Output } \\
\text { Rice quantity }{ }^{1} \text { (tons) }\end{array}$ & 290,808 & 52,994 & 329,872 & 60,296 & 391,150 & 80,437 & 315,270 & 57,785 \\
\hline Inputs & & & & & & & & \\
\hline Land $^{2}$ (hectares) & 134,629 & 23,192 & 144,944 & 25,893 & 212,785 & 56,497 & 145,685 & 26,699 \\
\hline Labor $^{3}$ (persons) & 168,703 & 27,044 & 163,805 & 26,208 & 160,163 & 25,683 & 155,159 & 24,486 \\
\hline Fertilizer $^{4}$ (tons) & 74,061 & 13,236 & 75,027 & 13,300 & 160,043 & 13,436 & 79,038 & 13,618 \\
\hline Pesticide $^{5}$ (tons) & 45,116 & 9610 & 47,926 & 10,021 & 52,205 & 10,596 & 56,117 & 11,047 \\
\hline Machinery ${ }^{6}$ (units) & 10,196 & 1937 & 12,213 & 2135 & 14,569 & 2394 & 16,762 & 2675 \\
\hline
\end{tabular}

Source: Measured by MS Excel 2016 using combined datasets of the Royal Government of Cambodia (RGC) [32,33]. "S.E." = Standard Error. ${ }^{1}$ Rice quantity was the total provincial un-milled rice production output quantity, measured in tons. ${ }^{2}$ Land input was the total area of rice actually harvested within the year (included both in wet and dry season), measured in hectares. ${ }^{3}$ Labor input measured as total farmers in the province with rice farming as primary occupation, unit in persons. ${ }^{4}$ Fertilizer input was total amount of chemical and organic fertilizers' quantity using by total rice families in the province, unit in tons. ${ }^{5}$ Pesticide input measured as total amount of chemical and organic poisons for insects and grass's quantity using by total rice families in the province, unit in tons. ${ }^{6}$ Machinery measured the capital investment on agricultural machineries was the total amount of tractors, walking tractors (koryons), and rice transplanting machines existing in the provincial territory, unit in units. 
Output quantity of rice production in Cambodia was higher in 2015 than in 2012, which increased $8.4 \%$ on average from 290 thousand tons (2012) to 315 thousand tons (2015). Total area of rice actually harvested on average also increased around 8\% from 134 thousand hectares in 2012 to 145 thousand hectares in 2015. Total rice families using quantities of chemical and organic fertilizers (i.e., fertilizer input), on the other hand, increased on average by $7 \%$, while pesticide and machinery input (definition same as above) increased greatly between this period. Total rice families using quantity of poison for insects and grass increased by nearly $25 \%$ (three times larger than land and fertilizer input), while the total capital investment on agricultural machineries between this period increased by a huge percentage of $64.4 \%$, indicating a huge improvement of mechanization in Cambodian agriculture, particularly in the rice production sector. Nevertheless, along with the improvement of agricultural mechanization, labor input which was measured as total people with rice farming as their primary occupation tended to slightly decrease by $8 \%$, presenting the progression of transformation of labor forces out of agriculture to other higher productivity and profitability sectors, such as industries and services.

Figure 1 illustrates the percentage changes of input and output statistics of Cambodian rice production between the study period 2012-2015. A closer look at percentage changes within output and input variables from year to year indicated that from 2012 to 2013, there were no significant changed within both output and input variables. However, there was a massive change in inputs, particularly in land and fertilizer between 2013 and 2014, which caused rice output to increase greatly. Unfortunately, the natural disasters (drought, flood, and insects) at the end of 2014 and in 2015 had destroyed a huge percentage of rice cultivated land in most leading rice production provinces (totally reducing around 30\% of 2014 production) and fertilizer input was also decreased greatly (by more than 50\%). Rice output, therefore, also decreased by a great percentage of $20 \%$. Conversely, development of capital investment in agricultural machineries still continued to increase by $15 \%-20 \%$ per year, while implementation of pesticide by farmers tended to increase $6 \%-9 \%$ annually as well. Labor input, on the other hand, had the decreasing trend from year to year in the percentage of $2 \%-3 \%$.

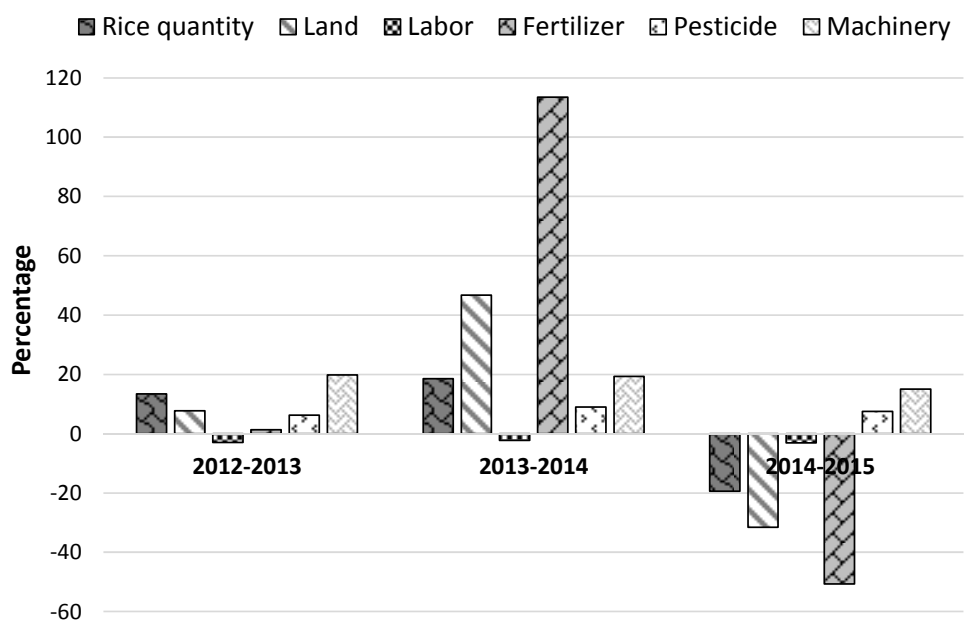

Figure 1. Percentage changes in input and output statistics for 25 rice producing provinces in Cambodia for the periods 2012-2013, 2013-2014, and 2014-2015.

In the technical inefficiency model (3), there were seven influencing factors of rice production TE to be considered in the present study. Disaster was measured as a percentage of rice production land damaged by floods, droughts, and insects to total rice production land actually harvested within the year. Apparently, disaster always caused the lower of harvested land to cultivated land ratio. Thus, disaster was expected to have a negative effect on rice production TE. Irrigation, on the other hand, measured as a percentage of provincial paddy land having or benefiting from irrigation systems (as well as paddy land located near water sources, such as rivers, lakes, ponds, etc.) to total provincial cultivated land within the year. Irrigation systems could cause the availability of rice cultivated land 
expansion by improving multi-cropping ${ }^{3}$; hence, irrigation was stalwartly expected to have a positive relationship with rice production TE. Additionally, production technique was measured as a percentage of families cultivating rice under the system of rice intensification (SRI) to total families cultivating rice. Under SRI, which introduced by MAFF with the support of CEDAC ${ }^{4}$, various rice cultivation techniques with less utilization of modern inputs and inexpensive methods of planting in relatively dry areas could result in an average yield of 3.6 tons / ha, while, under a similar situation, the yield with traditional farming practice is only 2.4 tons/ha [36]. Farmers cultivating rice under SRI were expected to have higher productivity than farmers using traditional techniques for cultivating rice. However, the percentage of families cultivating rice under this system still seems to be very low in Cambodia. Furthermore, farmers living in villages located closer to the center of district/khan might be able to get further and faster market information about rice; hence, this factor of distant to information sources was measured as average distance from village center to the center of district/khan (in kilometers). Agricultural staff, on the other hand, might have played some crucial roles for providing technical support as well as technical knowledge of rice production to the rural farmers. Thus, the number of agricultural supporting staff existing in the province was expected to have positive effects on TE of rice production. The variable of agricultural supporting staff was included in technical inefficiency model (3), measured as a percentage of agricultural staff included both government officers and NGOs staff (working on agricultural plans or projects) to total rice farmers existing in the province. Likewise, there are two main seasons in Cambodia, i.e., wet season and dry season. Greater availability of water resources during wet season have caused rice crops to be able to grow in every province of Cambodia. However, during dry season, only some provinces (as well as some parts of a province) where rice fields benefit from irrigation systems or are located near water sources could be able to cultivate rice crops. Dry season rice crops always provide higher yield of production, nonetheless it requires plenty of water and utilization of fertilizers, as well as higher commitments to for watching over it. However, rice production during the dry season in Cambodia was still highly dependent on availability of water resources during this season. Available land for cultivating rice during the dry season sometimes was in abundance due to the lack of water. Thus, the improvement of dry season rice was expected to have a positive effect on TE of rice production in Cambodia. The factor of $d r y$-season production measured as a percentage of dry season paddy land actually harvested to total available land for rice cultivation in dry season was correspondingly included in the model. The size of farm land owned by farmers was also expected to have a positive effect on rice production TE. The great percentage of rice farmers owning farm land less than one hectare, which might cause a limited ability for them to improve their rice production. This factor (small-land farmers) measured as a percentage of families having paddy land smaller than one hectare altogether with families having no paddy land to total rice families. Conversely, some external factors, such as social, economic, demographic, as well as geographic perspectives of each province were omitted from the technical inefficiency model (3), due to insufficient availability of appropriated datasets during the study period. Furthermore, the present study utilized only a four-year dataset of the entire 25 provinces of Cambodia, which limited availability of including too many influencing factors into the model, as it might cause unexpected conflicts or correlations among factor variables. Moreover, provinces of Cambodia were a bit tiny in areas and normally the local governance as well as the economy are still under direct control of the central government in Phnom Penh (i.e., provincial local governments in Cambodia are not very independent from each other like the situation in other countries like China, for instance). Therefore,

3 Multi-cropping: cropping/cultivating several times of crop on the same plot land.

4 CEDAC: Cambodian Center for Study and Development in Agriculture (Centre d'Etude et de Dévelopment Agricole Cambodgien). 
the present study assumed these external factors to be neutral to rice production TE. Thus, Equation (3) can be written as:

$$
u_{i t}=\delta_{0}+\delta_{1} \text { Disaster }_{i t}+\delta_{2} \text { Irri }_{i t}+\delta_{3} \text { Tech }_{i t}+\delta_{4} \text { Distant }_{i t}+\delta_{5} \text { Staff }_{i t}+\delta_{6} \text { Dry }_{i t}+\delta_{7} \text { SmallF }_{i t}
$$

Table 2 presents descriptive statistics of Cambodian rice production efficiency's influencing factors between 2012 and 2015. The percentage of rice land damaged by floods, droughts, and insects was lower in 2015 compared to 2012. Rice land damaged by disasters in 2012 was 18.8\% in average, while, in 2015 , disasters destroyed only $5.2 \%$ of rice production land on average (a decrease by $72.4 \%$ ). However, flooding in the wet season of 2014 has still destroyed almost $30 \%$ of total rice cultivated land within the year. These percentages still remain huge, which ought to be considered by the RGC and the related agencies. Furthermore, from 2012 to 2015, there were also large percentage changes in rural farmers' production techniques and amount of agricultural supporting staff existing in the province. Production techniques, which were measured as a percentage of families cultivating rice under SRI decreased greatly by $20 \%$ within three years, while percentage of agricultural supporting staff (to total rice families) also decreased by around 17\% during this period, indicating a lack of technical supporting techniques as well as technical improvement training for farmers with the purpose of improving the national rice production, particularly for small-land rural farmers, of which most of them are rice farmers. Although the percentage of small-land farmers (farmers owning no rice cultivated land or having rice land smaller than one hectare) have been slightly reduced during the study period (less than 5\%). In 2015, small-land farmers in Cambodia still accounted for $39.8 \%$ on average, which was still the vast percentage. Moreover, during the dry season, available land for cultivating rice was still not fully cultivated yet. In the study period 2012-2015, on average, more than 30\% of available dry season rice land was abundant annually. During 2012, on average, only $68.5 \%$ of the total available dry season rice production land had been actually cultivated, and this percentage became worse in 2013 (58.8\%). Although the situation had been slightly improved in 2014, while this percentage slightly increased to $65.1 \%$, water shortage during the dry season of 2015 had reduced the percentage of dry season actually cultivated land again to around $64.9 \%$. Therefore, there is still a huge gap for Cambodian famers to improve their rice production during dry season as well as total production of rice.

Table 2. Descriptive statistics of factors affecting the efficiency of rice production in Cambodia, 2012-2015.

\begin{tabular}{ccccccccc}
\hline \multirow{2}{*}{ Variable } & \multicolumn{2}{c}{2012} & \multicolumn{2}{c}{2013} & \multicolumn{2}{c}{2014} & \multicolumn{2}{c}{2015} \\
\cline { 2 - 8 } & Mean & S.E. & Mean & S.E. & Mean & S.E. & Mean & S.E. \\
\hline Disaster $^{1}$ & 18.86 & 12.34 & 5.16 & 1.12 & 30.98 & 26.37 & 5.20 & 1.16 \\
Irrigation $^{2}$ & 21.70 & 3.49 & 22.75 & 3.52 & 19.94 & 3.58 & 22.64 & 3.54 \\
Production technique $^{3}$ & 3.04 & 0.48 & 2.79 & 0.47 & 2.74 & 0.42 & 2.44 & 0.37 \\
Distance to info source $^{4}$ & 14.92 & 1.53 & 14.86 & 1.22 & 14.67 & 1.14 & 15.01 & 1.20 \\
Supporting staff $^{5}$ & 0.11 & 0.03 & 0.10 & 0.02 & 0.09 & 0.02 & 0.09 & 0.02 \\
Dry season production $^{6}$ & 68.47 & 5.72 & 58.76 & 6.33 & 65.12 & 5.89 & 64.91 & 6.43 \\
Small-land farmers $^{7}$ & 41.80 & 3.17 & 40.99 & 3.43 & 40.35 & 3.45 & 39.76 & 3.67 \\
\hline
\end{tabular}

Measured by MS Excel 2016 using combined datasets of RGC [32,33]. "S.E." = Standard Error. ${ }^{1}$ Disaster measured as a percentage of rice land damaged by floods, droughts, and insects to total rice actual harvested land within the year. ${ }^{2}$ Irrigation measured as a percentage of provincial paddy land having or benefit from irrigation systems as well as paddy land located near water sources to total provincial cultivated land within the year. ${ }^{3}$ Production technique measured as a percentage of families cultivating rice under the SRI system to total rice cultivated families ${ }^{4}$ Distance to information sources measured as average distance from village center to the center of district/khan (in kilometers). ${ }^{5}$ Agricultural supporting staff measured as a percentage of agricultural staff included both government officers and NGOs staff (working on agricultural plans or projects) to total rice farmers existing in the province. ${ }^{6}$ Dry-season production measured as a percentage of paddy land actually harvested during dry season to the total available cultivated land for rice cultivation during dry season. 7 Small-land farmers measured as a percentage of families having paddy land smaller than one hectare altogether with families having no paddy land to total rice families (i.e., families cultivating rice). 
Irrigation plays a very important role for rice production in Cambodia, particularly in the dry season. Between 2012 and 2015, irrigation systems were improved gradually by increasing the percentage of paddy land having irrigation systems from $21.7 \%$ in 2012 to $22.6 \%$ in 2015 (3.5\% increased within three years). However, this irrigation rate still seems to be very low compared to other agricultural nations, especially its neighboring countries like Thailand, and Vietnam, since another nearly $80 \%$ of total cultivated land is still being used as the rain-fed agricultural land. These statistics revealed that irrigation systems in Cambodia still remain lacking, with shortages far behind its potential to improve national rice production. In many developed countries, irrigation systems are not only used for agriculture, but are also being used as natural disaster prevention devices. Global climate change has been affecting Cambodia in the latest decade. Natural disasters like floods and droughts occurred more frequently than previously. Sometimes, within a year, Cambodian people suffered from flood in wet season, and then suffered again from droughts in dry season. This could be the result of irrigation system shortage, which caused Cambodia to have no ability to deal with such frequently occurring disasters. What if Cambodia could build irrigation and water storage systems in order to store over-needed water resources during the wet season and keep them for utilization in agriculture during the dry season?

\section{Results and Discussion}

\subsection{SFA Model Estimation}

Table 3 lists the parameters' estimation results by implementing the maximum likelihood estimation method in FRONTIER (version 4.1c) econometrics software of Coelli [30]. The variance ratio parameter of gamma $(\gamma)$ had a value of 1.00 and significance at $1 \%$, showing that the variation of the composite error term was mainly from the technical efficiency $\left(u_{i}\right)$ almost $100 \%$, and the variation of random error $\left(v_{i}\right)$ was less than $1 \%$, indicating that the efficiency source of Cambodian rice production within the study period came mainly from the production's technical efficiency.

Table 3. Parameter estimates of the SFA model.

\begin{tabular}{|c|c|c|c|}
\hline Variables & Coefficient & Standard Error & $t$-Ratio \\
\hline Constant & $-1.1869 *$ & 0.6189 & -1.9178 \\
\hline Ln(land) & $0.6796^{* * *}$ & 0.2475 & 2.7458 \\
\hline Ln(labor) & 0.0775 & 0.3279 & 0.2364 \\
\hline Ln(fertilizer) & $0.9245^{* *}$ & 0.4664 & 1.9820 \\
\hline Ln(pesticide) & $-1.8588^{* * *}$ & 0.3565 & -5.2139 \\
\hline Ln(machinery) & $1.8642^{* * *}$ & 0.2629 & 7.0914 \\
\hline$t$ & 0.0573 & 0.0369 & 1.5529 \\
\hline Land $\times$ Labor & $0.0420 * *$ & 0.0197 & 2.1339 \\
\hline Land $\times$ Fertilizer & $-0.0771 *$ & 0.0429 & -1.7966 \\
\hline Land $\times$ Pesticide & $0.1680^{* * *}$ & 0.0309 & 5.4381 \\
\hline Land $\times$ Machinery & $-0.1210^{* * *}$ & 0.0241 & -5.0263 \\
\hline Labor $\times$ Machinery & $-0.0585^{* *}$ & 0.0271 & -2.1577 \\
\hline$t^{2}$ & 0.0013 & 0.0068 & 0.1888 \\
\hline $\operatorname{Gamma}(\gamma)$ & $1.0000^{* * *}$ & 0.0001 & $13,538.2280$ \\
\hline Sigma-squared $\left(\sigma^{2}\right)$ & $0.0336^{* * *}$ & 0.0062 & 5.3882 \\
\hline Log likelihood function & & & 75.7787 \\
\hline
\end{tabular}

Almost all estimated coefficients have the expected signs. Total actual harvested land and agricultural machineries involved in rice production were both positively related to rice output and significant at $1 \%$, while the total amount of chemical and organic fertilizers' quantity use by total families in the province for the production of rice was also positively related but significant at $5 \%$. These results indicated that enlarging total actual harvested land, increasing capital investment in 
agricultural machineries and technically improving fertilizer application by smallholder rice producers (farmers) could result in increasing the output (quantity) of rice within the province. Moreover, with the estimated coefficient of 1.86, capital investment in agricultural machineries was the main input factor driving more output for Cambodia's provincial rice production compared to land and fertilizer input factor during the study period. This means that the provinces with higher capital investment (in agricultural machineries) tended to produce higher level of rice output than the provinces with lower capital investment.

Total actual harvested land was the second core input factor for increasing output of rice. The provinces that cultivate more additional land for rice have the ability to maintain reasonable levels of other necessary inputs in order to cause the rice output to increase faster than the provinces with low rates of rice cultivated land. These results confirmed the results of several previous studies, such as $\mathrm{Yu}$ and Diao [5], Smith and Hornbuckle [37] and some studies of Asian Development Bank [2,38]. Furthermore, total families using quantity of poison for insects and grass (included both chemical and organic poison) existing in the province, i.e., pesticides input factor, was negatively related to rice output and significant at $1 \%$, indicating that provinces with greater amounts of poison (pesticides) application tended to produce lower rice output than the provinces with smaller amounts of poison application. This could be the result of inefficient use of poison in rice production by farmers. It should be noted that most smallholder rice producers are farmers with little education. Furthermore, the instruction of product usage for most imported agricultural poison products have not yet been totally translated into the Khmer language before being imported (to Cambodia), which might cause numerous misunderstandings and lead to incorrect technical use as well as inefficient use in field practices by farmers. However, the study established that there was no significant relationship between rice output and the labor force involved in rice production.

Table 4 illustrates the input elasticities of rice production in Cambodia between 2012 and 2015. From this table, all input factors, except machinery, have had increasing return to scale to rice output, and elasticity of land input was the highest among all input factors, followed by fertilizer and labor input. Between the study period of 2012-2015, harvested land elasticity was 0.976 on average, indicating that 1 hectare increase in harvested land could cause rice output to increase by 0.976 tons, while the other input factors just had minor of elasticity value (less than 0.10). Input elasticities of machinery, on the other hand, were unexpectedly negative related to rice output during the study period of 2012-2015. As shown in the previous table (Table 3), machinery input had the highest positive coefficient of 1.86 (compared to other inputs) and was significant toward rice output at confidence level 99\%, indicating that the expansion of the amount of machinery used in rice farming could increase rice output level. However, a closer look at the relationship between machinery and another inputs, such as land and labor, indicated that machinery has had a negative (substitution) relationship with labor input, which was not surprising for most agricultural research that unskilled workers could be replaced by the utilization of machinery for gaining more output as well as saving more time. Likewise, machinery has also had a negative relationship with land input and was strongly significant at confidence level $99 \%$, which was quite surprising. Conversely, the ratio of investment level in agricultural machineries to total rice cultivated land in most high-potential provinces in the production of rice, such as Battambang, Banteay Meanchey, Kampong Thom, Kampong Cham, Prey Veng, Takeo, Svay Rieng, etc., seemed to be relatively low compared to some other provinces with lower potential for rice production like Phnom Penh suburbs and Pailin, for instance. This could explain the insufficient investment in machinery in the territory of high-potential provinces in rice production. Moreover, the negative relationship between land and machinery input (showed in Table 3) also indicated inefficienct performances of existing agricultural machineries for rice farming in high-potential provinces, which led to input elasticity of machinery input to be negative between the study period of 2012-2015. Thus, in addition to enlargement of investment in machineries for improving rice production in Cambodia (particularly in high-potential provinces), the techniques or solutions for increasing the performance efficiency of existing machineries as well as labor skills also needed to be considered (by related agencies). 
Table 4. Input elasticities of rice production in Cambodia, 2012-2015.

\begin{tabular}{cccccc}
\hline Year & Ln (Land) & Ln (Labor) & Ln (Fertilizer) & Ln (Pesticide) & Ln (Machinery) \\
\hline 2012 & 0.9898 & 0.0465 & 0.0569 & 0.0317 & -0.1701 \\
2013 & 0.9816 & 0.0340 & 0.0559 & 0.0339 & -0.1709 \\
2014 & 0.9694 & 0.0248 & 0.0537 & 0.0386 & -0.1729 \\
2015 & 0.9632 & 0.0156 & 0.0551 & 0.0356 & -0.1687 \\
\hline
\end{tabular}

Calculated by MS Excel 2016.

\subsection{Technical Efficiency Analysis}

The study indicated that individual provincial-level TE ranged from a low of $49.8 \%$ to a high of $99.7 \%$ with a mean technical efficiency of $79.5 \%$ in 2012. Rice production TE in 2015, on the other hand, ranged from a low of $36.8 \%$ to a high of $99.9 \%$ with a lower mean technical efficiency of $74 \%$ (a 7\% decrease). However, the findings revealed that the overall mean of rice production TE is estimated as 0.784 , which indicated that Cambodia produced $78.4 \%$ of rice at best at the current level of production inputs and technology. It means that rice output could have been increased further by $21.6 \%$ at the same levels of inputs if farmers had been fully technically efficient. There were only 10 out of 25 provinces that have had TE above the TE overall mean, while TE of another $60 \%$ of provinces still ranged below the average mean efficiency.

Figure 2 illustrates distribution of Cambodian rice production's TE from 2012 to 2015. Rice production in Cambodia performed very well during 2013, for which $40 \%$ of provinces had technical efficiency scores between 0.91 and 1.00, and another $28 \%$ had technical efficiency scored between 0.81 and 0.90 . Thus, in 2013, nearly $70 \%$ of provinces produced more than $80 \%$ of rice at current best practices at the current level of their production inputs and technology. However, natural disasters in 2014 and 2015 caused decreases in technical efficiency score in most Cambodian provinces.

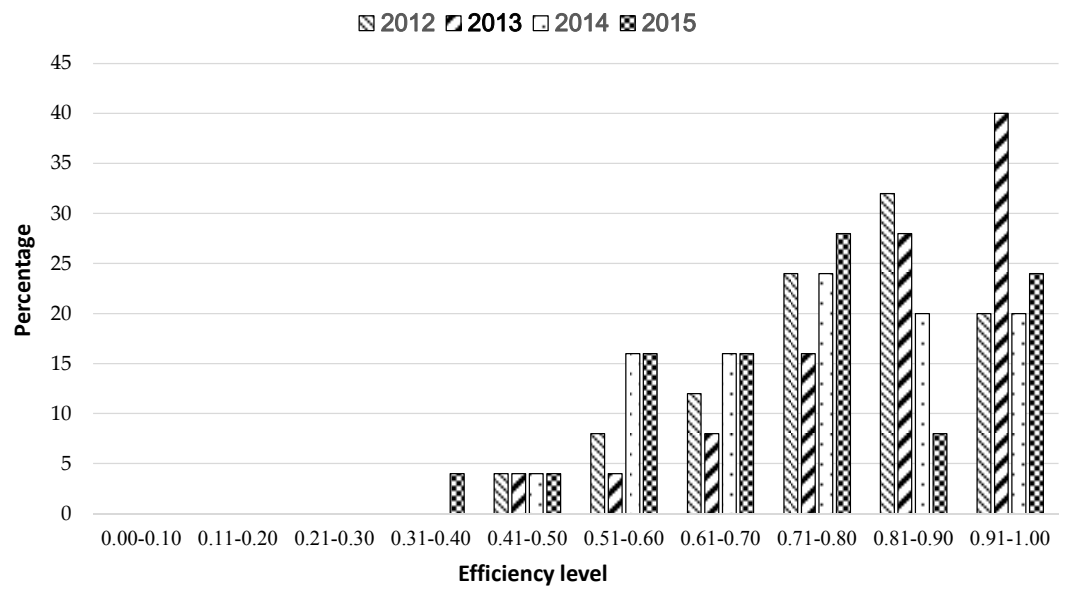

Figure 2. Technical efficiency distribution of rice production in Cambodia, 2012-2015.

Table 5 shows the rice production TE in different regions of Cambodia from 2012 to 2015. The results revealed that in the study period, Mekong plain, which is the second largest rice production region of Cambodia had the highest TE score in almost all years from 2012 (0.860) to 2015 (0.878) among all regions, and the only region that had an increasing TE score during the study period 2012 and 2015 (by 2.2\%). In 2015, all provinces in this region, except Svay Rieng province, had rice production TE more than $91 \%$. Takeo province was the most effective province in this region with the highest TE score of 0.999 , while Svay Rieng province's TE score in 2015 was just 0.599 . However, Tonle Sap plain which is the largest rice production region of Cambodia in the production area had a TE score of 0.814 in 2012, but decreased by $5.4 \%$ to 0.770 in 2015 as the results of natural disasters at the end of 2014 (flooded) and in 2015 (drought) that affected most provinces in this regions. The province with the highest TE 
score in this region in 2015 was Kampong Chhnang province (0.914), while Banteay Meanchey was the province that had the lowest TE score within the region.

Table 5. Regional technical efficiency of rice production in Cambodia, 2012-2015.

\begin{tabular}{cccccccccccc}
\hline \multirow{2}{*}{ Regions } & \multicolumn{2}{c}{$\mathbf{2 0 1 2}$} & \multicolumn{2}{c}{$\mathbf{2 0 1 3}$} & \multicolumn{2}{c}{$\mathbf{2 0 1 4}$} & \multicolumn{2}{c}{$\mathbf{2 0 1 5}$} & \multicolumn{3}{c}{ TE Change (\%) } \\
\cline { 2 - 12 } & $\mathbf{M}$ & S.E. & $\mathbf{M}$ & S.E. & $\mathbf{M}$ & S.E. & $\mathbf{M}$ & S.E. & $\mathbf{1 2 - 1 3}$ & $\mathbf{1 2 - 1 4}$ & $\mathbf{1 2 - 1 5}$ \\
\hline Phnom Penh $^{2}$ & 0.83 & 0.00 & 0.84 & 0.00 & 0.81 & 0.00 & 0.61 & 0.00 & 1.2 & -3.4 & -26.5 \\
Tonle Sap plain $^{1}$ & 0.81 & 0.05 & 0.87 & 0.04 & 0.71 & 0.05 & 0.77 & 0.04 & 6.8 & -12.4 & -5.4 \\
Mekong plain $^{2}$ & 0.86 & 0.07 & 0.89 & 0.10 & 0.88 & 0.07 & 0.88 & 0.07 & 3.2 & 2.6 & 2.2 \\
Mekong plateau $^{3}$ & 0.79 & 0.04 & 0.79 & 0.04 & 0.74 & 0.06 & 0.70 & 0.06 & 0.0 & -6.7 & -11.3 \\
Mountain $^{4}$ & 0.66 & 0.09 & 0.76 & 0.08 & 0.63 & 0.09 & 0.53 & 0.09 & 14.6 & -5.7 & -19.7 \\
Coastal $^{5}$ & 0.81 & 0.07 & 0.84 & 0.06 & 0.86 & 0.09 & 0.79 & 0.08 & 4.7 & 6.3 & -2.0 \\
Cambodia & 0.80 & 0.03 & 0.84 & 0.03 & 0.76 & 0.03 & 0.74 & 0.03 & 5.4 & -3.9 & -6.9 \\
\hline
\end{tabular}

Estimated by FRONTIER 4.1c. "M" = Mean; "S.E." = Standard Error; "12-13" = TE change between 2012 and 2013; "12-14" = TE change between 2012 and 2014; "12-15" = TE change between 2012 and 2015. ${ }^{1}$ Tonle Sap plain region included the province of Banteay Meanchey, Battambang, Kampong Chhnang, Kampong Thom, Pailin, Pursat, and Siem Reap. Total area: $61,510 \mathrm{~km}^{2}$ (accounted for $34.54 \%$ of the country's total area). ${ }^{2}$ Mekong plain included the province of Kampong Speu, Kandal, Prey Veng, Svay Rieng, and Takéo. Total area: 21,997 km² $(12.35 \%) .{ }^{3}$ Mekong plateau included the province of Kampong Cham, Kratié, Stung Treng, and Tbong Khmoum. Total area: $31,663 \mathrm{~km}^{2}(17.78 \%) .{ }^{4}$ Mountain region included the province of Mondulkiri, Ratanakiri, Preh Vihear, and Oddar Meanchey. Total area: $45,016 \mathrm{~km}^{2}(25.28 \%) .{ }^{5}$ Coastal region included the province of Kampot, Koh Kong, Kep, and Preah Sihanouk. Total area: 17,237 km² (9.68\%).

\subsection{Technical Inefficiency Model and Affecting Factors}

Table 6 presents the parameters of the rice production's technical inefficiency model estimated by FRONTIER version 4.1c. In the model specification, it is obvious that irrigation and production techniques both had negative coefficient signs and were significant at $1 \%$, while agricultural supporting staff also had negative coefficient signs but were significant at $5 \%$, indicating positive relationships of these three factors to TE of rice production in Cambodia. These results revealed that development of irrigation systems and good water management practices, development of rice production technique to the rural farmers, and increasing the number of agricultural supporting staff in the provincial territory are the three core factors to cause rice production TE to increase. With the highest coefficient of 0.95 and 0.08 , the factor of agricultural supporting staff and production technique played as the first and second core affecting factors, respectively. Provinces with more agricultural supporting staff existing and higher rates of families using SRI tended to have higher TE scores than provinces with less amount of supporting staff and lower rate of families using SRI, which indicated the importance of technical supporting services from agricultural staff (both government officers and NGOs staff) and new production technique implementation in rice production. These coefficient values ( 0.95 and 0.08 for agricultural supporting staffs and production technique respectively) indicated that $1 \%$ increase of the percentage of agricultural supporting staff (to total farmers cultivating rice) within the provincial territory and the percentage of families cultivating rice under the SRI system to total rice cultivated families could cause the increase of rice production TE by $0.95 \%$ and $0.08 \%$, respectively.

Irrigation, on the other hand, served as the third core affecting factor of Cambodian rice production TE. Having a coefficient of 0.01 revealed that a $1 \%$ increase of the percentage of provincial paddy land having or benefiting from irrigation systems (to total provincial cultivated land) within the year could push TE of provincial rice production to increase by $0.01 \%$. In Cambodia, irrigation is mainly used for dry season rice and to complete wet season rice if necessary. It is also an essential component to ensure that farmers can grow crops during the dry season. The ADB [2] argued that rice production's efficiency in Cambodia is always constrained by low-rates of irrigation, while Smith and Hornbuckle [37] suggested that rice yields could be improved by helping to better regulate water inputs. Khmer farmers are mostly able to cultivate rice only once per year because of inadequate irrigation systems and good water management practices. 
Table 6. Rice production technical inefficiency model parameter estimation.

\begin{tabular}{cccc}
\hline Variables & Coefficient & Std. Error & $t$-Ratio \\
\hline Constant & $0.9241^{* * *}$ & 0.1484 & 6.2261 \\
Disaster & 0.0003 & 0.0005 & 0.5641 \\
Irrigation & $-0.0119^{* * *}$ & 0.0026 & -4.5368 \\
Production technique & $-0.0841^{* * *}$ & 0.0283 & -2.9688 \\
Distant to information sources & -0.0052 & 0.0060 & -0.8703 \\
Agricultural supporting staff & $-0.9530^{* *}$ & 0.4032 & -2.3635 \\
Dry season production & -0.0016 & 0.0016 & -1.0549 \\
Small-land farmers & -0.0007 & 0.0036 & -0.2056 \\
\hline
\end{tabular}

Estimated by FRONTIER 4.1c. ${ }^{*}$ indicates significant at $10 \%,{ }^{* *}$ significant at $5 \%$, and ${ }^{* * *}$ at $1 \%$.

Rice production in Cambodia still seems to be vulnerable to natural disasters, such as floods and droughts. As discussed previously, irrigation systems and good water management practices were not only the core factors for improving rice production in Cambodia, but also the main disaster prevention devices for protecting Cambodia from natural disasters. Although percentage of rice land area damaged by floods, drought, and insects did not significantly affect rice production TE during the study period, frequently occurring natural disasters still indirectly affect the rice production due to lack of irrigation systems. For instance, disasters occurring in the wet season of 2014 (flooded) and in 2015 (drought) destroyed thousands of hectares of rice fields, causing a decrease in total land actually harvesting rice, which was the second core input factor for increasing rice output after capital investment in agricultural machineries. Although average rice yield and rice price still continued to increase between 2014 and 2015 , frequently occurring of natural disasters still led the production of rice to decrease gradually from 2014 to 2015. Irrigation systems, therefore, should be the core factor to be considered and bring about actions by the RGC and the related agencies. Conversely, the study established that there was no significant relationship between the factors of distance from information sources, dry season production, amount of small-land farmers and rice production TE.

\section{Conclusions}

The aim of this paper was to estimate the TE of rice production in Cambodian and determine its main influencing factors by using the SFA model. The present study utilized a four-year dataset generated from the central government document "Profile on Economics and Social" of all 25 provinces between 2012 and 2015. The results indicated that the level of rice output in Cambodia varied according to the different level of capital investment in agricultural machineries, total rice actual harvested area, and technical fertilizer application within provinces. The mean TE of rice production is 0.784 , which means that famers in this region produce rice $78.4 \%$ efficiently with best practices at the current level of production inputs and technology. This means that rice output has the potential of being increased by a further $21.6 \%$ at the same level of inputs if farmers had been technically efficient. However, during the study periods, the TE of rice production recorded a $7 \%$ decreasing rate. Takeo province was the most effective province nationwide, while another $60 \%$ of provinces still had TE below the average mean efficiency in 2015.

Three main conclusions emerged from the study's results. First, based on decomposing the SFA model, enlarging capital investment at the provincial level into agricultural machineries is the core input factor influencing rice production in Cambodia, while the expansion of total rice land actual harvested area, and technical improvement of fertilizer application range were the second and third core input factors, respectively. These results are not very surprising since they are straightforward techniques for increasing rice productivity in most developing countries in the world. Likewise, these results also confirmed the existing problems in Cambodian rice production sector, which were previously addressed by relevant studies [1,2,5,37,38]. However, agricultural mechanization in Cambodia still faces numerous challenges including: (1) the national policy on agricultural mechanization 
is not yet prepared; (2) the structure of the Provincial Office of agricultural engineering is still weak; (3) inadequate skilled workforce at both national and provincial levels; (4) credit scheme for buying farm machinery and equipment is non-existent; (5) most of the workshops for repairing and maintenance of farm machinery and equipment are not available in the rural areas; (6) annual budget allocated for the implementation of agricultural mechanization activities fails at nationwide coverage; (7) less activities in research and development on agricultural machinery and equipment, and they exist mainly at the national level; (8) external support and cooperation with development partners is still missing; and (9) there are gaps in cooperation with the private sector dealing with farm machinery [39]. Local manufacturers of farm machineries and equipment usually produce threshers, water pumps, locally made trucks for transportation, trailers, implements and spare parts such as cage wheels. Nonetheless, they can manufacture only simple machines that do not require sophisticated production processes or tools. Normally, they are still small scale and family owned with a few workers, and operate seasonally for supplying local markets [40]. Thus, large-scale machineries, such as tractors, walking tractors (koryons), etc., are still being imported from major countries including Belorussia, China, Japan, India, US and Thailand. This revealed the lack of ability as well as local technical experts for Cambodia to be able to manufacture large heavy-scale agricultural machineries by itself. Financial institutions (microfinances and commercial banks) are the major sources of credit for making machinery purchases for farmers. Conversely, due to Cambodia not yet having had any agricultural bank to support credit schemes for buying farm machinery and equipment, farmers have had to use their own savings or borrow from existing financial institutions or dealers to buy new machines, where often they are provided with relatively higher interest rates for loans (on average $24 \%$ per year) compared to neighboring countries like Vietnam (less than $1 \%$ per year). Harvested area, on the other hand, had the highest elasticity among all input factors of rice production in Cambodia. It is clearly indicated that increasing harvested area (i.e., land input) could cause the increase of rice output at a higher percentage than all other inputs. However, although the RGC has been trying to increase rice production by enlarging the total area of rice fields annually, this enlargement still remains far behind its enormous potential to increase rice productivity. Therefore, significant commitments and supported actions are required to address the problem.

Second, production techniques for rural farmers, technical skills and amount of agricultural supporting staff are the most important influencing factors of rice production in Cambodia. Although SRI has been introduced before 2008, the percentage of farmers cultivating rice under this system still seems to be low. Enlarging percentage of farmers cultivating rice under the SRI instead of traditional rice cultivating techniques by the widespread introduction of this system to rural farmers, together with the strengthening technical skills of agricultural supporting staff, and building up of stronger relationships between rural farmers and supporting staff, as well as the relationships between the related agencies, might be the best solution for this. Likewise, extra research and development in new production techniques of rice cultivation are still needed for improving rice productivity. Finally, the agricultural sector as well as rice production in Cambodia is always inevitably linked to development of irrigation systems and good water management practices. Nonetheless, several constraints in irrigation development still exist. Irrigation systems in Cambodia are still in development and do not provide coverage for the whole country due to a lack of supporting financial resources and technical experts. Moreover, most farmers' paddy fields are small and lack road access systems for paddy fields far from the road. In addition, there is a lack of drainage systems for paddy fields and sometimes rainfall during harvesting, which also remain as constraints to progress. Development of irrigation systems and good water management practices are therefore of relevant magnitude to be heavily considered by policy makers for developing strategic policies geared towards enhancing rice production.

Therefore, the main factors affecting the output level of rice production in Cambodia appear to be capital investment in agricultural machineries as well as efficiency of machinery performance, actual harvested area, and fertilizer utilization, while irrigation and good water management, 
production techniques, and technical supporting staff serve as main factors affecting TE of rice production in Cambodia.

In conclusion, in addition to capital investment, and improving technical skills for both supporting staff and rural farmers in order to improve rice productivity in Cambodia, the present study recommends that the development of irrigation systems and good water management practices be strongly considered and bring about more effective actions by the central government as well as related agencies for preventing frequently occurring natural disasters and increasing actual harvested area, particularly in the dry season.

Acknowledgments: This study was a part of the project "the study on the production factors allocation efficiency and its growth road of south area's household agricultural production under the situation of the new return of collective forestry reform" funded by the China's National Science Foundation and the Northwest A\&F University of China.

Author Contributions: Author contribution to the present study as follow: "Sokvibol Kea and Hua Li conceived and designed the study and survey; Sokvibol Kea performed the survey and gathered the data; Sokvibol Kea and Linvolak Pich analyzed the data; Sokvibol Kea, Hua Li, and Linvolak Pich contributed reagents/materials/analysis tools; finally, Sokvibol Kea wrote the paper."

Conflicts of Interest: The authors declare no conflict of interest.

\section{References}

1. Cambodia Development Resource Institute (CDRI). Annual Development Review 2011-2012; Cambodia Development Resource Institute (CDRI): Phnom Penh, Cambodia, 2012.

2. Asian Development Bank (ADB). Improving Rice Production and Commercialization in Cambodia; Asian Development Bank (ADB): Mandaluyong, Philippines, 2014.

3. Central Intelligence Agency. The World Factbook. Available online: https://www.cia.gov/library/ publications/the-world-factbook/geos/cb.html (accessed on 10 January 2015).

4. The World Bannk. GDP Per Capita, PPP (Current International \$). Available online: http://data.worldbank. org/indicator/NY.GDP.PCAP.PP.CD?order=wbapi_data_value_2013+wbapi_data_value+wbapi_data_value -last\&sort=desc (accessed on 10 January 2015).

5. Yu, B.; Diao, X. Cambodia's Agricultural Strategy: Future Development Options for the Rice Sector; Cambodia Development Resource Institute (CDRI): Phnom Penh, Cambodia, 2011.

6. Liu, M.; Li, D. An Analysis on Total Factor Productivity and Influencing Factors of soybean in China. J. Agric. Sci. 2010, 2, 158-163. [CrossRef]

7. NIS. Cambodia General Population Census 2008. Available online: http://celade.cepal.org/redkhm/census / khm2008/ (accessed on 10 January 2015).

8. NIS. Cambodia General Population Census 1998. Available online: http://celade.cepal.org/redkhm/census/ khm1998/ (accessed on 10 January 2015).

9. Nesbitt, H.J. Rice Production in Cambodia; International Rice Research Institute (IRRI): Manila, Philippines, 1997.

10. Sawaneh, M.; Latif, I.A.; Abdullah, A.M. Total Factor Productivity of Rice Farming in Selected Southest Asian Countries. In Proceedings of the International Conference on Social Science Research, ICSSR 2013, Penang, Malaysia, 4-6 June 2013.

11. Food and Agriculture Organization. FAO Statistical Yearbook 2010; Food and Agriculture Organization of the United Nations: Rome, Italy, 2010.

12. Fulginiti, L.E.; Perrin, R.K. Agricultural productivity in developing countries. Agric. Econ. 1998, 19, 45-51. [CrossRef]

13. Coelli, T.J.; Rao, D.S.P.; O'Donnell, C.J.; Battese, G.E. An Introduction to Efficiency and Productivity Analysis, 2nd ed.; Springer: Berlin, Germany, 2005.

14. Nin-Pratt, A.; Yu, B.; Fan, S. The total factor productivity in China and India: New measures and approaches. China Agric. Econ. Rev. 2008, 1, 9-22. [CrossRef]

15. Coelli, T.J. Recent Developments in Frontier Modeling and Efficiency Measurement. Aust. J. Agric. Econ. 1995, 39, 219-245. [CrossRef] 
16. Yang, W.; Shao, Y.; Qiao, H.; Wang, S. An Empirical Analysis on Regional Technical Efficiency of Chinese Steel Sector based on Network DEA Method. Procedia Comput. Sci. 2014, 31, 615-624. [CrossRef]

17. Svitalkova, Z. Comparison and Evaluation of Bank Efficiency in Selected Countries in EU. Procedia Econ. Financ. 2014, 12, 644-653. [CrossRef]

18. Detotto, C.; Pulina, M.; Brida, J.G. Assessing the productivity of the Italian hospitality sector: A post-WDEA pooled-truncated and spatial analysis. J. Product. Anal. 2013, 42, 103-121. [CrossRef]

19. Fu, P.; Zhan, Z.; Wu, C. Efficiency Analysis of Chinese Road Systems with DEA and Order Relation Analysis Method: Externality Concerned. Procedia Soc. Behav. Sci. 2013, 96, 1227-1238. [CrossRef]

20. Cullmann, A.; von Hirschhausen, C. Efficiency analysis of East European electricity distribution in transition: Legacy of the past? J. Product. Anal. 2007, 29, 155-167. [CrossRef]

21. Mayston, D.J. Analysing the effectiveness of public service producers with endogenous resourcing. J. Product. Anal. 2015, 44, 115-126. [CrossRef]

22. Lin, B.; Long, H. A stochastic frontier analysis of energy efficiency of China's chemical industry. J. Clean. Product. 2015, 87, 235-244. [CrossRef]

23. Manlagñit, M.C.V. Basel regulations and banks' efficiency: The case of the Philippines. J. Asian Econ. 2015, 39, 72-85. [CrossRef]

24. Manlagñit, M.C.V. Cost efficiency, determinants, and risk preferences in banking: A case of stochastic frontier analysis in the Philippines. J. Asian Econ. 2011, 22, 23-35. [CrossRef]

25. Zheng, S.; Bloch, H. Australia's mining productivity decline: Implications for MFP measurement. J. Product. Anal. 2013, 41, 201-212. [CrossRef]

26. Ondrej, M.; Jiri, H. Total Factor Productivity Approach in Competitive and Regulated World. Procedia Soc. Behav. Sci. 2012, 57, 223-230. [CrossRef]

27. Yao, S.; Li, H. Agricultural productivity changes induced by the sloping land conversion program: An analysis of Wuqi county in the Loess Plateau region. Environ. Manag. 2010, 45, 541-550. [CrossRef] [PubMed]

28. Aigner, D.J.; Lovell, C.A.K.; Schmidt, P. Formulation and Estimation of Stochastic Frontier Production Function Models. J. Econ. 1977, 6, 21-37. [CrossRef]

29. Meeusen, W.; van den Broeck, J. Efficiency Estimation from Cobb-Douglas Production Functions with Composed Error. Int. Econ. Rev. 1977, 18, 435-444. [CrossRef]

30. Coelli, T.J. A Guide to FRONTIER Version 4.1: A Computer Program for Stochastic Frontier Production and Cost Function Estimation; University of New England: Armidale, Australia, 1996.

31. Coelli, T. Estimators and hypothesis tests for a stochastic frontier function: A Monte Carlo analysis. J. Product. Anal. 1995, 6, 247-268. [CrossRef]

32. The Royal Government of Cambodia (RGC). Profile on Economics and Social in Year 2015, Based on Commune Databaes (CDB), December Year 2014 (Khmer language). Provincial Profile on Economics and Social; Ministry of Planning (MoP) of The Royal Government of Cambodia (RGC): Phnom Penh, Cambodia, 2015.

33. The Royal Government of Cambodia (RGC). Profile on Economics and Social in Year 2016, Based on Commune Databaes (CDB), December Year 2015 (Khmer language). Provincial Profile on Economics and Social; Ministry of Planning (MoP) of The Royal Government of Cambodia (RGC): Phnom Penh, Cambodia, 2016.

34. Baldwin, K.; Childs, N.; Dyck, J.; Hansen, J. Southeast Asia's Rice Surplus; United States Department of Agriculture (USDA), Economic Research Service: Washington, DC, USA, 2012.

35. Wikipedia. Green Revolution. Available online: https://en.wikipedia.org/wiki/Green_Revolution (accessed on 8 September 2016).

36. Centre d'Etude et de Dévelopment Agricole Cambodgien. Report on the Progress of System of Rice Intensification in Cambodia 2007; Cambodian Center for Study and Development in Agriculture (Centre d'Etude et de Dévelopment Agricole Cambodgien): Phnom Penh, Cambodia, 2008.

37. Smith, D.; Hornbuckle, J. A Review of Rice Productivity in Cambodia and Water Measurement Using Direct and Indirect Methods on a Dry Season Rice Crop; Technical Report to ACIAR: Canberra; CSIRO Sustainable Agriculture Flagship: Australia, 2013. Available online: https://publications.csiro.au/rpr/download?pid= csiro:EP1310226\&dsid=DS6 (accessed on 29 September 2016). 
38. Asian Development Bank. The Rice Situation in Cambodia; Technical Assistance Consultant's Report of Asian Development Bank (ADB), 2012. Available online: https://www.adb.org/sites/default/files/projectdocument/73081/43430-012-reg-tacr-01.pdf (accessed on 3 October 2016).

39. Chan, S. Agricultural Mechanization in Cambodia: Challenges and opportunities. Regional Forum on Sustainable Agricultural Mechanization in Asia and the Pacific; Ministry of Agriculture, Forestry and Fisheries (MAFF): Phnom Penh, Cambodia, 2013.

40. Chan, S. Agricultural Mechanization in Cambodia. The 2nd Regional Forum on Sustainable Agricultural Machanization-Enabling Environment for Custom Hiring of Agricultural Machinery; Agricultural Engineering Department of Ministry of Agriculture, Forestry and Fisheries of Cambodia (MAFF): Phnom Penh, Cambodia, 2014.

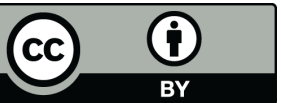

(C) 2016 by the authors; licensee MDPI, Basel, Switzerland. This article is an open access article distributed under the terms and conditions of the Creative Commons Attribution (CC-BY) license (http://creativecommons.org/licenses/by/4.0/). 